\title{
AOR
}

Selected Papers of \#AolR2021:

The 22nd Annual Conference of the

Association of Internet Researchers

Virtual Event / 13-16 Oct 2021

\section{MAPPING HEALTH: HOW DANES EXPERIENCE THEIR DIGITAL HEALTH DATA}

\author{
Martina Skrubbeltrang Mahnke \\ Roskilde University, Denmark \\ Mikka Nielsen \\ University of Copenhagen, Denmark
}

This paper explores how Danish citizens experience digital health data and how these in turn affect their understanding of digital health data and their self-understanding as a patient.

Denmark is a unique case as it is ranked as one of the most digital countries in the world (European Commission, 2018). Examining the national health platform sundhed.dk (sundhed is the Danish word for health) is hence of great value with regards to shedding light on the ramifications of digital health data. The platform was launched in 2003 by the Danish Regions, the Ministry of Health and local authorities with the primary political aim to support Danish citizens to "master their health" (sundhed.dk's strategy, 2019-2022), and further to support an informed relationship between the medical system and patients. The platform provides access to medical data in the form of lab results, doctor's notes, a medical dictionary and further functionalities such as an overview of doctor's appointments. Having access to one's own health data enables the patient to research and read about diagnoses, treatment options, and prognosis, at home, independent of scheduled doctor appointments.

Previous research on digital health data examines primarily opportunities and challenges as well as structural effects (Fisher \& Britten, 1993; Fisher, Bhavnani \& Winfield, 2009; Woods et al., 2013) concluding that having access to one's medical data is generally beneficial for patients but also comes with literacy challenges. Petersen (2018) points out that the sole access to data does not necessarily lead to better and more informed decisions, on the contrary, a variety of skills and competences are needed in order to make sense of medical data. Research on selftracking applications shows that digital health data creates a certain self-awareness that leads towards routine behavior and self-performance (Lupton, 2016; Williamson, 2015). In addition, digital health data can be accessed any time anywhere, which makes the process of engaging with digital health data and using it purposefully even more demanding. Even though Danes are amongst the most tech-savvy in Europe, they are also struggling with using and making sense of their digital health data (author removed). The aim of this research is to look deeper into personal experiences with digital health data in order to understand what is at stake when people become digitally mapped patients and how experiences of empowerment, independence, perplexity, and doubt intermingle when reading one's own health data. Taking a user's view, the paper draws theoretically on the concept of 'assemblage' (Johnson, 2019)

Suggested Citation (APA): Mahnke, M. S., Nielsen, M. (2021, October). Mapping Health: How Danes Experience Their Digital Health Data. Paper presented at AoIR 2021: The 22nd Annual Conference of the Association of Internet Researchers. Virtual Event: AolR. Retrieved from http://spir.aoir.org. 
understanding digital health data as a complex nexus of user-data relationships. That is to say, data is subject to social, cultural and political influences and can hence only be understood in the respective context. Digital health data arises at the nexus of the medical system, human actors and technical structure. Lupton (2018) has argued that digital data confronts its users to know themselves better. However, as the medical system operates with a variety of methods and theories it is often hard for patients to understand the data when accessing it. The concept of 'assemblage' accounts for the complexity of digital health data, pointing towards the layers and number of relationships that lie in such data.

The empirical analysis draws on 16 in-depth purposefully sampled interviews (Cresswell, 1998) with users varying in age, education, health history and gender. In total, 10 women and 6 men between the age of 24 and 74 were interviewed. All interviews were transcribed and have been coded thematically in several iterative steps (Kvale and Brinkmann, 2009). We further scrutinized the interview data for specific emotionally challenging experiences users had when engaging in their health data. In a last step during the analysis overarching themes and topics were identified and brought together in an assemblage.

The primary analysis shows that digital health data creates unique, deeply emotional experiences that can lead towards a variety of existential questions. One of our informants, for example, checked her health data during Christmas holidays and found that doctors suspected her cancer to be of a particular aggressive kind. Reading the doctor's notes left a deep emotional mark while simultaneously raising a number of questions. Therefore our informant started searching the diagnosis on the web, trying to collect as much information as possible. Another informant went through psychological treatment, and the platform offered her insight into the protocols made by the psychologist. While reading the psychologist's notes the informant started to wonder about the impression she makes on others while simultaneously questioning the medical way of dealing with her as a patient. She describes the experience as extremely ambiguous.

Combining the theoretical lens with the empirical analysis this paper contributes towards the field with what we call 'health assemblages' that highlight the emerging relationships and personal emotional attachments users make with their digital health data. In the following, we present an assemblage mapping of a list of topics that describe patients experiences with their digital health data:

- Ambiguity (digital health data is experienced in various, often opposing, ways)

- Deeply emotional (digital health data evokes strong emotions)

- Empowerment (digital health data provides self-knowledge)

- Recognition (digital health data supports self-understanding)

- Doubt (digital health data leaves patients with a number of questions)

- Frustration (digital health data is subject to personal interpretations, which leads to frustration)

In conclusion, it can be stated that seeing oneself mapped in data creates unique experiences, often challenging the self-understanding of the patient. On the positive side patients' access to digital health data may foster experiences of empowerment and recognition, but on the negative side, it potentially leaves the patient insecure, puzzled and with more questions than answers. Independence, in a way, encompasses both sides of the spectrum. 


\section{References}

Cresswell, J. W. (1998). Qualitative inquiry and research design: Choosing among five traditions. London: Sage.

European Commission. (2018). International Digital Economy and Society Index 2018. https://ec.europa.eu/knowledge4policy/publication/international-digitaleconomy-society-index2018 en

Fisher, B., Bhavnani, V., \& Winfield, M. (2009). How patients use access to their full health records: a qualitative study of patients in general practice. Journal of the Royal Society of Medicine, 102 (12), 539-544. https://doi.org/10.1258/jrsm.2009.090328

Fisher, B., Britten, N. (1993). Patient access to records: expectations of hospital doctors and experiences of cancer patients. The British Journal of General Practice, 43 (367), 52-56.

Johnson, E. (2019). Posthumanism, materialitet och människa. In: G. Erlingsdóttir. \& H. Sandberg (Eds.), På tal om e-hälsa, Studentlitteratur, pp. 177-192.

Kvale, S \& Brinkmann, S. (2009). InterViews: Learning the craft of qualitative research interviewing. Los Angeles: Sage.

Lupton, D. (2018). How do data come to matter? Living and becoming with personal data. Big Data \& Society, 5(2). https://doi.org/10.1177/2053951718786314

Petersen, A. (2018): Digital Health and Technological Promise: A Sociological Inquiry. London: Routledge.

Sundhed.dk's strategy (2019-2022). Available at:

https://www.sundhed.dk/content/cms/16/75816_sundheddks-strategi-2019-2022.pdf

Williamson, B. (2015). Algorithmic Skin: Health-Tracking Technologies, Personal Analytics and the Biopedagogies of Digitized Health and Physical Education. Sport, Education \& Society, 20 (1), 133-51.

Woods, S., Schwartz, E., Tuepker, A., Press, N., Nazi, K., Turvey, C., \& Nichol, W. (2013). Patient experiences with full electronic access to health records and clinical notes through the My HealtheVet Personal Health Record Pilot: qualitative study. Journal of Medical Internet Research, 15(3), e65. https://doi.org/10.2196/jmir.2356 